\title{
PENGARUH SOSIOLOGIS KOMUNITAS LESBIAN GAY BISEKSUAL DAN TRANSGENDER DITINJAU DALAM ETIKA KRISTEN
}

\author{
Ekker Saogo ${ }^{1 *)}$ \\ Sekolah Tinggi Teologi Amanat Agung ${ }^{1}$ \\ *)Email Correspondence:ekkersaogo92@gmail.com
}

\begin{abstract}
The Lesbian, Gay, Bisexual and Transgender (LGBT) in the past this was as something deviant, but nowadays it has become a trend that is even considered natural by many people. This of course has a sociological impact. There is a view that says that the behavior of LGBT people is a biological natural behavior, so it needs to be accepted as something that cannot be changed. Some theories agree that LGBT behavior is influenced by environmental, parenting, and economic factors, so that there are pros and cons for LGBT people. This study aims to see the sociological influence of the LGBT community by using a literature review. The results of the study show that LGBT is contrary to the truth of God's creation, namely the clear separation of sex, namely male and female. Also, this is contrary to the design of marriage that God built, namely heterosexuality and monogamy.

Keywords: Sociological Influence, LGBT, Christian Ethics.

Abstrak: $\quad$ Komunitas Lesbian, Gay, Biseksual dan Transgender (LGBT) pada masa yang lalu dianggap sebagai sesuatu yang menyimpang, namun masa kini hal menjadi sebuah trend yang bahkan dianggap wajar oleh banyak orang. Hal ini tentu memberi dampak secara sosiologis. Muncul pandangan yang mengatakan bahwa perilaku kaum LGBT adalah perilaku alamiah secara bilogis, sehingga perlu diterima sebagai hal yang tidak dapat diubah. Beberapa teori setuju bahwa perilaku LGBT dipengaruhi oleh faktor lingkungan, pola asuh, dan ekonomi, sehingga muncul pro dan kontra bagi kaum LGBT. Penelitian ini bertujuan untuk melihat pengaruh sosiologis komunitas LGBT dengan menggunakan kajian literatur. Hasil penelitian menunjukkan bahwa LGBT bertentangan dengan kebenaran penciptaan yang dilakukan oleh Allah yaitu dengan pemisahan seks dengan jelas yaitu laki-laki dan perempuan. Juga hal ini bertentangan dengan rancangan pernikahan yang Allah bangun yaitu heteroseksualitas dan monogamis

Kata Kunci: Pengaruh Sosiologis, LGBT, Etika Kristen.
\end{abstract}

\section{PENDAHULUAN}

Lesbyan Gay Biseksual Transgender (LBGT) adalah fenomena yang

berkembang di tengah masyarakat dewasa masa kini. LGBT merupakan bentuk penyimpangan seksual. ${ }^{1}$ LGBT menjadi sebuah trend yang menarik dan bahkan

1 Stephen Tong, Rahasia Kemenangan Cinta Dan Seks Menuju Pernikahan (Surabaya: Momentum, 2012), 7. 
dianggap sebagai hal yang wajar. Keberadaan kaum LGBT terus bertambah dan tak dapat terhindarkan. Eksistensi kaum LGBT secara umum memberikan pengaruh pada kehidupan anak muda secara umum, juga generasi muda Kristen secara khusus, sehingga komunitas LGBT berpotensi memberi pengaruh negatif. ${ }^{2}$ Kaum LGBT dapat memberikan pengaruh secara biologis, psikologis dan sosiologis. Hal ini tentu perlu mendapat perhatian dari semua kalangan.

Gunawan Saleh berpendapat bahwa semua agama sepakat bahwa LGBT merupakan perilaku seksualitas yang menyimpang. ${ }^{3}$ Selain itu Tri Ermayani berpendapat bahwa LGBT bertentangan dengan tujuan Pendidikan nasional, sebagaimana yang ditegaskan dalam Undang-Undang No. 20 tahun 2003 pasal 3 bahwa: Pendidikan Nasional berfungsi mengembangkan kemampuan dan watak serta peradaban bangsa yang bermanfaat dalam rangka mencerdaskan kehidupan bangsa, yang bertujuan untuk mengembangkan potensi peserta didik agar menjadi manusia yang beriman dan bertaqwa kepada Tuhan Yang Maha Esa, berkahlak mulia, sehat, berilmu, cakap kreatif dan mandiri dan menjadi warga negara yang demokratis dan bertanggung jawab. Dengan tujuan ini maka, LGBT membuat kecerdasan menurun, tidak memiliki kepribadian yang utuh dan bertentangan dengan hukum negara dan hukum agama.

Sebuah penelitian mengemukakan bahwa pola asuh yang salah dapat mempengaruhi perkembangan individu dan berdampak bagi pola perilaku. Orang tua dan guru memegang peranan penting bagi aspek pertumbuhan dan perkembangan (Spritual, fisik, kejiwaan, intelektual, emosi sosial, seksual dan

\footnotetext{
2 Wawan Setiawan dan Yudhitiya Dyah Sukmadewi, "'Peran Pancasila Pada Era Globalisasi' Kajian Terhadap Pancasila Dan Fenomena Lgbt (Lesbian, Gay, Bisexual, Transgender) Di Indonesia," Jurnal Dinamika Sosial Budaya 19, no. 1 (2017): 126, http://dx.doi.org/10.26623/jdsb.v19i1.691.

3 Gunawan Saleh dan Muhammad Arif, "Fenomenologi Sosial Lgbt Dalam Paradigma Agama," Jurnal Riset Komunikasi 1, no. 1 (28 Februari 2018): 88, https://doi.org/10.24329/jurkom.v1i1.16.
} 
ekonomi) tujuannya adalah agar anak dapat menyadari sejak dini akan bahaya yang ditimbulkan akibat perilaku LGBT. ${ }^{4}$

Ada beberapa aspek yang menjadi salah satu penyebab berkembangnya LGBT. Sosial media menjadi salah satu penyebab maraknya trend pencarian mengenai LGBT. ${ }^{5}$ Salah satu topik hangat dalam polemik seputar LGBT adalah faktor genetis di balik perilaku homoseksualitas, beberapa riset medis dilakukan untuk menemukan alasan dan penyebab. Sherwood mengemukakan bahwa penjelasan biologis memberikan sebuah alasan yang dapat diterima terhadap perilaku homoseksual, yaitu jika dilahirkan dalam kondisi demikian. Penjelasan ini memiliki implikasi politik dan sosial sehubungan dengan kriteria legal dan keputusan pengadilan yang digunakan dalam menyusun undang-undang hak sipil dalam melindungi kelompok minoritas. ${ }^{6}$ Disamping itu dukungan medis menunjukkan bahwa LGBT memang secara intrinsik berbeda dengan yang lain. Jadi banyak pendukung LGBT yang memakai hasil riset medis ingin memberi dukungan bahwa gaya hidup sebagai seorang LGBT bukanlah sebuah pilihan, namun sebuah konsekuensi alamiah yang tidak dapat dihindarkan.

Selanjutnya beredar keputusan beberapa pejabat Persekutuan GerejaGereja Indonesia (PGI) yang menerima kaum LGBT. Surat penggembalaan terhadap kaum LGBT dinilai kurang mempertimbangkan pandangan gereja-gereja yang menjadi anggota PGI yang menolak eksistensi kaum LGBT. Pandangan dan keputusan PGI tahun 2019 telah menimbulkan kebingungan terhadap banyak

4 Tri Ermayani, "LGBT dalam Perspektif Islam," Humanika, Kajian IImiah Mata Kuliah Umum 17, no. 2 (2017): 147, https://doi.org/10.21831/hum.v17i1.18569.

5 Eko Yulian, "Text Mining dengan K-Means Clustering pada Tema LGBT dalam Arsip Tweet Masyarakat Kota Bandung," Jurnal Matematika "MANTIK" 4, no. 1 (11 Mei 2018): 53, https://doi.org/10.15642/mantik.2018.4.1.53-58.

${ }^{6}$ Sherwood O. Cole, "The Biological Basis of Homosexuality: A Christian Assessment," Journal of Psychology and Theology 23, no. 2 (Juni 1995): 95, https://doi.org/10.1177/009164719502300202. 
masyarakat. Uniknya alasan PGI membela orientasi seksual LGBT didasakan pada Alkitab dan kondisi LGBT yang dianggap sebagai korban yang mendapat penolakan atas orietasi seksualnya. Tidak hanya itu PGI juga mendasarkan penerimaan terhadap kumunitas LGBT didasarkan pada sumber umum, sosial, moral, kedokteran dan psikiatri. Merespon hal tersebut Binsar Antoni Hutabarat menuliskan evaluasi terhadap tindakan para beberapa oknum PGI yang berpihak pada penerimaan LGBT, bahwa apapun alasan kedokteran dan psikiatri dalam menerima LGBT termasuk faktor biologis hal tersebut tetaplah tidak dapat dibenarkan sebab itu adalah dosa dihadapan Tuhan. ${ }^{7}$ Jika hal tersebut dilanggar jelas sudah melawan Tuhan dan pasti hal tersebut adalah dosa.

Memang beberapa penelitian dilakukan untuk membenarkan bahwa LGBT merupakan perilaku alamiah dari setiap individu, namun haruslah diingat bahwa mencampuradukkan perilaku seksual dan orentasi seksual memiliki kelemahan, artinya hal ini tidak membuktikan bahwa homoseksualitas dipengaruhi oleh faktor biologis, jadi dapat disimpulkan bahwa hasil riset medis terhadap kaum homoseksualitas belum berhasil membuktikan bahwa homoseksualitas disebabkan oleh faktor genetis. Penelitian terus dilakukan, hingga kini belum ada penjelasan ilmiah yang sangat akurat yang dapat menjelaskan apa yang menjadi penyebab homoseksualitas. Adanya faktor biologis, psikologis, sosiologis, sosiohistoris yang turut membentuk orentasi seksual dan identitas gender.

Dengan demikian jelas bahwa persoalan LGBT mendapat sorotan dari berbagai pihak, teori-teori yang mendukung agar melegalkan LGBT ataupun konsep-konsep yang dibangun untuk menolak perilaku ini tentunya memiliki

7 Binsar Antoni Hutabarat, "Evaluasi terhadap Rumusan Pernyataan Pastoral PGI Tentang Lgbt," Societas Dei: Jurnal Agama dan Masyarakat 6, no. 2 (2019): 151, https://doi.org/10.33550/sd.v6i2.124. 
dampak bagi kaum LGBT itu sendiri. Dalam konteks sosiologis salah satunya ialah kehidupan keluarga telah mendapat pengaruh dari kaum LGBT, maraknya pernikahan sesama jenis banyak terjadi. Terkait hal tersebut Subeno Sujipto menegaskan dalam bukunya yang berjudul indahnya pernikahan Kristen bahwa dalam melakukan hubungan seksual hal tersebut harus dilakukan antara laki-laki dan perempuan (suami istri) dan bukan antara sesama jenis. ${ }^{8}$ Dengan demikian eksistensi kaum LGBT secara sosiologis mereka berada disekitar kehidupan orang percay dan terlibat interaksi setiap hari, hal ini berpotensi memberi pengaruh serta dampak bagi orang generasi muda Kristen. Oleh karena itu melalui tulisan ini menjelaskan pengaruh sosiologis LGBT ditinjau dari etika Kristen.

\section{METODE}

Metode penelitian yang digunakan adalah studi literatur. Pendekatan studi kepustakaan ini dipilih untuk menambah dan melengkapi data-data baik melalui buku maupun artikel jurnal. Hal tersebut untuk memberi jawaban atas topik yang diteliti sehingga menghasilkan jawaban dari pertanyaan penelitian berdasarkan sumber-sumber yang ada. Penulis mengumpulkan data dari sejumlah literatur untuk kemudian ditinjau dan dianalisis terkait dengan pengaruh sosiologis komunitas LGBT ditinjau dalam etika Kristen. Data-data yang dianalisis dengan metode Miles dan Huberman dimana di dalamnya mencakup pengumpulan data, analisis data, reduksi data, penyajian data dan penarikan kesimpulan. ${ }^{9}$

8 Subeno Sutjipto, Indahnya Pernikah Kristen (Surabaya: Momentum, 2010), x.

${ }^{9}$ Matthew B. Miles, A. Michael Huberman, dan Johnny Saldana, Qualitative Data Analysis: A Method Sourbook (Canada: Sage Publication, 2019), x. 


\section{HASIL}

Karya ilmiah ini meneliti pengaruh sosiologis komunitas LGBT ditinjau dalam etika Kristen. Hasil penelitian ini memberikan pemikiran tentang betapa pentingnya gereja untuk memberikan perhatian pada kaum LGBT dan generasi selanjutnya. Pengaruh sosiologis dari komunitas LGBT ini sangat cepat sehingga kelompok LGBT berani menyatakan identitas kepada masyarakat. Kaum LGBT mendasarkan tuntutan pada hak asasi manusia (HAM), meminta agar keberadaan mereka sebagai LGBT diterima dan diakui oleh masyarakat seperti layaknya kelompok heteroseksual lainnya. Tidak hanya itu akibat pengaruh dari komunitas LGBT yang menganggap bahwa orientasi seksual adalah wajar jelas sangat mempengaruhi perkembangan pertumbuhan mental seorang anak lainnya dalam hal identitas, merusak pola pikir dan nilai-nilai hukum dan religi. Hal tersebut juga mempengaruhi hubungan dalam hal relasi sosial.

Hasil penelitian ini memberikan kontribusi pemikiran agar komunitas LGBT yang sudah ada tidak di diskrimasi, tidak dibenci oleh gereja melainkan dikasihi. Penelitian ini juga menghasilkan konsep pemikiran bagi gereja dalam melayani komunitas LGBT, mereka harus diselamatkan, dikasihi dan diberikan pendampingan pastoral sampai kembali pada jati diri sesuai Alkitab. Selanjutnya penelitian ini mendeskripsikan fenomena pengaruh relasi buruk dari kaum LGBT yang berdampak pada kerusakan mental dan spiritual anak maupun orang dewasa, hal ini sangat diperlukan sebab pengaruh komunitas LGBT itu sendiri sangat kuat. Dengan demikian penelitian ini mendasarkan pandangan etika Kristen terhadap LGBT. Tinjauan etika Kristen terhadap pengaruh komunitas LGBT dengan mendeskripsikan manusia sebagai laki-laki dan perempuan. Menjelaskan orientasi 
seks dan gender serta hakikat pernikahan sebagai lembaga pertama yang dicitapkan oleh Tuhan. Sehingga hasil dari penelitian ini bersifat kontributif dengan maksud memberikan solusi agar prinsip etika Kristen menjadi pondasi utama dalam berselasi.

\section{PEMBAHASAN}

Pada bagian lain Penulis membahas tentang tinjauan etika Kristen terhadap LGBT sebagai dasar berpijak terhadap hal-hal penting yang perlu diperhatikan dalam etika kristen. Penulis membahas penciptaan manusia sebagai laki-laki dan perempuan yang telah diciptakan oleh Allah, membahas sex dan gender manusia serta tujuan penciptaan Allah terhadap manusia yaitu mempersatukan laki-laki dalam sebuah keluarga demi kemuliaan-Nya. Pada bagian akhir Penulis membahas bagaimana pengaruh sosiologis dari komunitas LGBT.

\section{Pengertian LGBT}

Istilah "Homoseksualitas" pertama kali muncul di Jerman pada tahun 1869 dalam sebuah surat terbuka yang ditulis oleh Karl Maria Kertbeny dan ditujukan pada pejabat hukum. ${ }^{10}$ Walaupun istilah ini baru muncul pada abad ke-19 Masehi, namun gaya hidup seksualitas sendiri telah dijalani oleh sebagian orang sejak lama, sehingga tidak salah jika Alkitab mengajarkan bahwa tidak ada yang baru di bawah matahari (Pkh. 1: 9). Jika seorang laki-laki berperilaku seperti perempuan maka dapat disebut dengan istilah banci. Kosakata yang sama digunakan untuk

10 Francis M Mandimore, Natural History of Homosexuality (London: The John Hopkins University Press, 1996), 3. 
beragam perilaku yang lain yang sejenis. ${ }^{11}$ Pengetian LGBT oleh Amerika Psychiatry Association: Lesbian: perempuan yang memiliki dorongan seksual dan keterikatan emosional dengan perempuan lain. Gay: laki-laki yang memiliki dorongan seksual dan keterikatan emosional dengan laki-laki lain. Bisexual: orang yang memiliki dorongan seksual dan keterikatan emosional dengan lawan jenis maupun sesama jenis. Transgender: orang yang identitas atau ekspresi gendernya berbeda dengan ciri-ciri seksual secara bilogis dari orang itu. ${ }^{12}$

Para ahli memberikan pandangan mengenai LGBT, yaitu: Karl Maria Kertbeny mengemukakan LGBT ada dalam tiga kategori yaitu monoseksual, heteroseksual dan heterogeny. ${ }^{13}$ Magnus Hirscfeld menjelaskan faktor lain yang dapat mempengaruhi LGBT adalah faktor lingkungan. ${ }^{14}$ Berbeda dengan Kinsey mengatakan bahwa perilaku LGBT dipengaruhi oleh budaya, sosial, agama, ideologi hukum dan ekonomi. ${ }^{15}$ Salah seorang ahli psikologi Freud berpendapat bahwa gay sebagai akibat dari pola asuh yang salah dari sang ayah. Seorang yang mengalami kekerasan, maka secara kondisi anak ini dianggap gagal mendapatkan figur seorang ayah sehingga dalam dirinya muncul rasa mencintai diri sendiri atau mencintai sosok laki-laki. Freud mengatakan bahwa kondisi biseksual merupakan hasil dari prediposisi sewaktu kecil. Hal ini berkembang bagi kehidupan anakanak yang berada dalam lingkungan tententu. Gangguan seperti ini terjadi akibat

\footnotetext{
11 Yakub Tri Handoko, Memikirkan Ulang Homoseksualitas (Surabaya: Gratia Fidei, 2016), 6.

12 Chuck Stewart, Homosexuality and Law: A Dictionary (Santa Barbara: Oxford University Press, 2001), $x$.

13 P Wedanthi dan IGA Fridari, "Dinamika Kesetiaan Pada Kaum Gay," Jurnal Psikologi Udayana 1, no. 2 (2014): 363, https://doi.org/10.24843/JPU.2014.v01.i02.p15.

14 Silvia Ekasari, "Potensi Meningkatnya Beban Eonomi Akibat Fenomena Pertumbuhan LGBT di Kota Depok," Jurnal Manajemen Riset Bisnis Indonesia 10, no. 6 (2019): 21, https://journal.stiembi.ac.id/index.php/jmrbi/article/view/8/8.

${ }^{15}$ Alfred C Kinsey, Wardell B Pomeroy, dan Clyde E Martin, "Sexual Behavior In The Human Male," The Journal of Nervous and Mental Disease 109, no. 3 (1949): 283, https://ajph.aphapublications.org/doi/10.2105/AJPH.93.6.894.
} 
ketidakmatangan sesksual yang menghasilkan kondisi homoseksual ketika dewasa. Kondisi ini juga dapat terjadi apabila seseorang mengalami trauma pada masa kecilnya dimana pernah merasakan penyiksaan dari saudara kandung, teman ataupun orang tua. ${ }^{16}$

Dari beberapa pengertian dan pendapat para ahli, maka dapat ditarik kesimpulan bahwa LGBT merupakan sebuah perilaku penyimpang terhadap seks dan orentasinya yang dapat mempengaruhi perkembangan fisik, emosi, psikis bahkan sosial. Beberapa hal yang dapat memicu terjadi pola perilaku menyimpang ini adalah polah asuh yang keliru, adanya trauma masa lalu, lingkungan pergaulan, dan ekonomi.

\section{Pandangan Etika Kristen terhadap LGBT}

Perlu dipahami bahwa dalam beretika tidak hanya bicara soal baik buruknya tindakan sesorang, etika perlu mempertanyakan dasar dibalik prinsip moral tersebut dan etika juga memiliki hubungan dengan relasi manusia dengan sesamanya. Etika dapat dipandang sebagai refleksi atas tindakan dalam relasi antara "is" dan "ough" artinya, nilai kebaikan diperoleh dalam realitas (is) yang daripadanya kemudian ditarik prinsip baik buruk dari tindakan-tindakan yang deskriptif, evaluative, maupun normative (ough). Karena itulah penting memahami etika dengan baik sehingga setiap manusia yang berakal budi dapat mempertanggungjawabkan tindakannya secara rasional tetapi juga berdiri atas dasar kebenaran. ${ }^{17}$ Depok," 22.

16 Ekasari, "Potensi Meningkatnya Beban Eonomi Akibat Fenomena Pertumbuhan LGBT di Kota

17 Xaverius Chandra, Etika Sosial (Surabaya: Juli 2016), 4-5 (Surabaya: Fakultas Filsafat Widya Mandala, 2016), 4-5, http://repository.wima.ac.id/id/eprint/14407/7/BAHAN\%20AJARETIKA\%20SOSIAL.pdf. 
Etika Kristen didasarkan pada kebenaran Alkitab sebagai Firman Allah. Setiap perkataan, tindakan dan emosi perlu sesuai dengan Firman Tuhan. Alkitab menjadi dasar setiap orang dalam bertindak dan berprilaku dengan benar (Lih. Fil.4: 8). Dalam dosa manusia suka memikirkan apa yang jahat dan tidak benar di mata Tuhan. Dalam ayat tersebut Paulus mengajak jemaat Filipi belajar mengontrol dan melatih pikiran untuk hal-hal yang baik. Banyak hal yang dilakukan dipicu dan dikendalikan oleh pikiran. Apabila memikirkan yang benar, adil dan suci dan maka manusia juga melakukan hal-hal yang benar. Karena itu pikiran perlu diterangi oleh kebenaran Allah.

Kaum LGBT memperlihatkan bahwa yang dipikirkan dan dikerjakan menjadi bagian dari natur sebagai LGBT. Berprilaku bertindak sebagai LGBT bukanlah suatu kesalahan. ${ }^{18}$ Gregory mengungkapkan bahwa hidupnya kacau dan tersiksa saat tahu bahwa orientasi seks kepada sesama jenis. Namun setelah bergumul sekian lama dan tidak keluar dari keadaan sebagai gay dan tetap memilih menjadi gay, dengan dasar Tuhan mengasihi semua orang termasuk gay. ${ }^{19}$ Namun kebenaran tidak dapat didasarkan pada perasaan, hati, pikiran diri sendiri melainkan pada kebenaran Allah yang ada dalam Alkitab (Bdk. Ams. 28: 26a).

Homoseksual merupakan satu prilaku yang menghambat heteroseksual seseorang dalam rancangan Allah sejak awal mula penciptaan. Terhambatnya heteroseksual merupakan pengaruh dalam emosi perkembangan heterosesksual, sehingga terjadinya homokseksual bukan merupakan bawaan lahir melainkan disebabkan terjadinya penyimpangan, demikian kata William dalam bukunya

${ }^{18}$ N N, Tindakan LGBT, diwawancara oleh Ekker Saogo, Telephone, 2021.

19 Gregory Coles, Gay Selibat Kristen (Jawa Timur: Perkantas, 2019), 78-81. 
yang berjudul Tidak Lagi Homo. ${ }^{20}$ Kaum LGBT dikategorikan sebagai kaum minoritas yang sah, walaupun mereka mendapat teguran, kritikan bahkan diskrimansi dari banyak masyarakat mereka tetap merasa bahwa kelompok mereka adalah sah adanya, walaupun dalam pandangan banyak orang mereka minoritas. Hal ini dikemukakan langsung oleh Donal Webster bahwa kaum LGBT adalah kaum minoritas yang resmi. Sehingga dari tahun ketahun pendukung kelompok LGBT memberanikan diri bersuara untuk tidak diperlakukan diskrimansi. $^{21}$

Dalam pandangan ilmu hukum LGBT merupakan suatu amoralitas yang tidak sesuai dengan nilai-nilai dan kaidah-kaidah baik dalam nilai pancasila dan agama. Namun di mata hukum tidak semua LGBT dapat didiskriminasi karena delik aduan terkait dengan diskriminasi tersebut haruslah terukur. ${ }^{22}$ Hukum pidana yang berlaku terhadap LGBT ada dalam pasal 292 KUHP yakni "orang dewasa yang melakukan perbuatan cabul dengan orang lain sesama kelamin yang diketahuinya atau sepatutnya harus diduga belum dewasa, diancam paling lama lima tahun penjara." ${ }^{23}$ Kriminalisasi LGBT harus dipertimbangkan dengan melihat berbagai aspek, baik nilai sosial dan budaya tertentu.

Orang Kristen yang menentang LGBT dipandang oleh para pendukung LGBT sebagai pelanggar hukum kasih, lebih jauh dituding telah menghalangi orang lain mengasihi sesama. Para penentang LGBT dinilai tidak hidup seperti Tuhan Yesus dan ajaran-Nya yang menerima orang berdosa. Dalam terang firman

20 William Consiglio, Tidak Lagi Homo. (Bandung, Anggota IKAPI, 1998), 21 (Bandung: Kalam Hidup, 1998), 21.

21 Meilanny Budiarti Santoso, "LGBT dalam Perspektif Hak Asasi Manusia," Share: Social Work Journal 6, no. 2 (2016): 222, https://doi.org/10.24198/share.v6i2.13206.

22 Ari Wibowo, "Tinjauan Teoritis Terhadap Wacana Kriminalisasi Lgbt," Jurnal Cakrawala Hukum 11, no. 1 (2017): 96, https://ejournal.up45.ac.id/index.php/cakrawala-hukum/article/view/191/176.

23 Wibowo, 96. 
Allah yang tampak alamiah belum tentu ideal atau sempurna. Akibat kejatuhan manusia dalam dosa maka membawa pengaruh dan dampak buruk yang komprehensif. Seluruh alam tercemar oleh dosa, Semua elemen dalam diri manusia pikiran, perasaan, kehendak dan tubuh rusak oleh dosa (Rom. 3: 10-18, Ef. 4: 17-19).

Alkitab memandang homoseksual adalah dosa dan ini merupakan kekejian bagi Tuhan (Im. 18: 22). Rujukan dosa Sodom yang bernatur seksual terdapat juga dalam Kitab Yehezkiel 16: 47-50. Kata "keji” diterjemahkan dalam bahas Ibrani to'ebah kata ini digunakan untuk menjelaskan baik laki-laki atau perempuan dan sesama jenis saat bersetubuh dapat disebut "kekejian". Dosa Sodom ada banyak, yaitu keangkuhan, ketidakadilan sosial dan mengumbar prilaku homoseksual. Dosa Sodom dicatat dalam Alkitab dosa percabulan yang mengerikan. ${ }^{24}$ Hal yang sama diungkapkan Thomas Hubbart bahwa kota Sodom merupakan sebutan untuk dosa seksual dan sangat mungkin untuk dosa homoseksual. ${ }^{25}$ Artinya aktivitas homoseksual itulah yang terlihat jelas dalam kota Sodom.

Dalam kitab Imamat 19 Sodom dan Gomora adalah dua kota yang memiliki nama yang lebih buruk di dalam seluruh Alkitab. Dalam pasal ini Tuhan menurunkan hujan belerang dan api ke atas mereka, ini merupakan suatu hukuman yang dahsyat atas kejahatan mereka yang tidak tahu malu itu. Dalam keseluruhan Alkitab Sodom dan Gomora adalah sinonim untuk dosa yang besar (Yes.1: 9-10; 39; Yer. 23: 19; Yeh. 16: 44-58). Dalam Perjanjian Baru Yesus sering merujuk pada Sodom dan Gomora ketika memperingatkan orang banyak

24 Deyong Deyong, Apa Yang Sebenarnya Alkitab Ajarakan Mengenai Homoseksualitas? (Surabaya: Momentum, 2016), 31-32.

25 Thomas K Hubbard, ed., Homosexuality in Greece and Rome: A Sourcebook of Basic Dokuments (Berkeley: University of California Press, 2003), 384. 
akan murka Allah atas orang-orang yang keras hati (Mat. 10: 14-15). Bahkan di masa kini Sodom dan Gomora menjadi kiasan untuk dosa dan penghakiman.

Imamat 20: 13 menyatakan bila seorang laki-laki tidur dengan laki-laki maka keduanya melakukan suatu kekejian dan pasti dihukum mati dan darah mereka tertimpa kepada mereka sendiri. Artinya homoseksualitas melanggar kekudusan umat Allah. Kata "kudus" atau "kekudusan" muncul sebanyak delapan puluh tujuh kali dalam kitab Imamat. Kekudusan adalah tema utama, keseluruhan penyembahan atau ibadah Israel mengasumsikan kekudusan Allah. ${ }^{26}$ Arti ayat tersebut menjelaskan bahwa seorang laki-laki tidak boleh berhubungan seks dengan sesama jenisnya. Frasa "secara orang bersetubuh dengan perempuan" mengingatkan akan kejadian 2, di mana Allah menciptakan perempuan pertama dari tulang rusuk laki-laki sehingga perempuan itu akan menjadi seorang penolong bagi laki-laki. Bangsa Israel harus kudus sebab Allah itu kudus. Sebagai bangsa yang dikuduskan, umat Allah harus berbeda dengan bangsa dan budaya disekitar mereka.

Perjanjian Baru menyatakan pernikahan sejenis tidak hanya merupakan kekejian bagi Tuhan tetapi prilaku tersebut merupakan suatu pemberontakan, perlawanan, penyangkalan manusia terhadap Allah (Rom. 1: 26-27). Dalam Roma 1: 18 Paulus berbicara soal murka Allah, kemarahan Allah terhadap kefasikan, kelaliman, penyembahan berhala dan sekaligus terhadap prilaku homoseksualtias. Manusia mengaku mengenal Allah tetapi tidak memuliakan Dia sebagai Allah, pikiran manusia menjadi tumpul, bodoh dan gelap. Karena itu Paulus menutup Pasal 1 ini dengan tegas bahwa orang yang melakukan hal-hal demikian patut

26 Hubbard, 37-38. 
dihukum mati, mereka bukan saja melakukannya sendiri tetapi mereka juga setuju dengan mereka yang melakukkannya. Tidak melakukan namun menyetujui, tindakan tersebut sama saja. Borrong mengatakan dalam bukunya bahwa ada dua alasan sebab homoseksual dipandang sebagai sesuatu yang negatif. Pertama lakilaki dan perempuan diciptakan oleh Tuhan untuk suatu tujuan yakni memiliki keturunan melalui perkawinan antara laki-laki dan perempuan. Tetapi oleh karena heteroseksual terhambat sehingga tindakan homoseksual dapat terjadi. Sehingga perbuatan atau tindakan tersebut merupakan hal negatif dalam pandangan Alkitab. Kedua Pelarangan untuk prilaku homoseksual selalu disebut sebagai kerangka pelarang untuk semua jenis penyimpangan seksualitas. ${ }^{27}$

Kevin Deyoung mendefinisikan dua kata dalam Bahasa Yunani untuk menjelaskan tentang homoseksualitas yakni kata "arsenokoitai" dan "malakoi" (1Kor. 6: 9-10; dan 1 Tim. 1: 8-11). ${ }^{28}$ Kata "arsenokoitai" merupakan gabungan dari laki-laki (arsen) dan ranjang (koite) yang berarti menjadi "penidur laki-laki" atau "mereka yang membawa laki-laki ke ranjang." Kemungkinan Paulus mengatakan istilah ini sebab dia adalah orang Yahudi, suku Benyamin dididik oleh Gamaliel yang terkenal dan dididik menurut hukum ketat dari nenek moyangnya (Kis. 22: 3; Fil. 3: 5-6). Kata tersebut juga merujuk pada homoseksual yang terdapat dalam Imamat 18 dan 20. Kata kedua ialah "malakoi" yang berarti tunduk untuk disentuh dan menjadi pasif di dalam hubungan sesama jenis. Kata ini memiliki arti 'halus' seperti pakaian yang halus (Luk.7: 25) atau banci seperti seorang laki-laki yang dipenetrasi (seperti seorang perempuan) oleh laki-laki lain. Paulus menggunakan kata itu untuk merujuk pada laki-laki yang sudah membuat 
diri terlalu feminin dalam hal penampilan dan berprilaku. Namun tidak hanya itu, Paulus juga berpandangan bahwa merupakan aib bagi laki-laki jika memilih gaya rambut seperti perempuan (1Kor. 11: 14). Memang hal ini tidak membahayakan dalam kekekalan nemun menjadi aneh jika berpikir dan berprilaku berbeda dari keadaan atau natur yang sesungguhnya. Itu artinya aktivitas homoseksual bukanlah berkat untuk dirayakan dan ditetapkan melaikan sebuah dosa yang harus dipertobatkan, ditinggalkan dan diampuni.

Kaum LGBT menjadi perbincangan di Indonesia. Satu sisi ada yang menerima dan yang lain menolak. Dan secara umum keberadaan kaum LGBT mendapat penolakan dari gereja, membiarkan dan ada yang memberikan hukuman. Sikap gereja tidak memperlihatkan sebagai gereja yang memiliki kasih. Karena itu kaum LGBT adalah orang yang memerlukan perhatian, sentuhan kasih dalam wujud pelayanan pendampingan pastoral. Kaum LGBT perlu dirangkul, dikasihi dan pelayanan kepada mereka juga harus dilakukan dengan penuh kehatihatian agar mereka merasakan nyaman diperlakukan di dalam kasih Kristus. $^{29}$ Dwi Hartati Mengemukakan bahwa LGBT adalah sebuah dosa yang melawan Allah dan bertentangan dengan Alkitab. Gereja harus bertanggungjawab menolong dan memulihkan mereka. Sebab LGBT itu sendiri adalah penyakit yang perlu disembuhkan. Gereja harus mengajar mereka agar mengerti kitab suci dengan baik sehingga dapat hidup dalam kebenaran Firman Tuhan. ${ }^{30}$

\section{Tinjauan Etika Kristen Terhadap Komunitas LGBT}

29 Agung Gunawan, "Pendampingan Pastoral bagi Kaum Lesbian, Gay, Bisexual dan Transgender," Jurnal Theologi Aletheia 18, no. 1 (2016): 12-13, http://sttaletheia.ac.id/wpcontent/uploads/2016/10/Pendampingan-Pastoral-bagi-Kaum-Lesbian-Gay-Bisexual-dan-Transgender.pdf.

30 Sri Dwi Harti, "Pentingnya Pelayanan Pastoral Terhadap Korban LGBT," jurnal Luxnos 6, no. 2 (2020): 201-2, https://doi.org/10.47304/jl.v6i2.55. 
Tinjauan etis terhadap komunitas kaum LGBT dalam perspektif etika Kristen didasarkan pada penyataan Alkitab terkait dengan penciptaan manusia yaitu laki-laki dan perempuan, seks dan gender dan hakikat pernikahan.

\section{Penciptaan Laki-Laki Dan Perempuan}

Alkitab mencatat bahwa Allah adalah Pencipta (Kej.1: 1), yang menciptakan segala sesuatu dan diakhir penciptaan berkata "sungguh amat baik." Secara khusus manusia diciptakan lebih dari pada ciptaan lainnya. Laki-laki dan perempuan diciptakan serupa dan segambar dengan Allah (imagodei). Dengan jelas Alkitab mencatat bahwa Allah menciptakan manusia dengan dua jenis kelamin yaitu laki-laki dan perempuan. Penyebutan secara eksplisit dalam penciptaan "laki-laki" dan "perempuan" merupakan salah satu keunikan penciptaan manusia dengan makhluk ciptaan yang lain. Itu artinya tidak ada jenis kelamin yang netral yang diciptakan oleh Tuhan. ${ }^{31}$

\section{Seks dan Gender}

Allah telah menciptakan seks yang pada dasarnya suci bukan sebagai sesuatu yang jahat ataupun hina karena itu seks yang kudus tersebut harus dipakai dalam ikatakan suami istri yang telah menikah sebagai bentuk kesatuan, ungkapan kasih sayang, relasi dan tentu meneruskan keturunan. Tulus Tu'u menjelaskan ada tiga pandangan yang salah tentang seks. Pertama, seks dianggap hanya sebagai dorongan jasmani saja. Kedua, Seks dianggap sebagai hal yang kotor dan tabuh. Ketiga, seks dipandang hanya sebagai kenikmatan. ${ }^{32}$ Berdasarkan pandangan tersebut di atas menunjukkan bahwa sejatinya manusia tidak dapat dipisahkan

31 Tumini Sipayung dan Roma Sihombing, "Pandangan Teologis Terhadap Penyakit Menular Covid-19 Sebagai Problema Global," Lembaga Penelitian dan Pengabdian Masyarakat Politeknik Unggul 7,

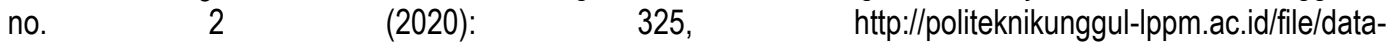
jurnal/6db19eb3ca9ad55b16d9ae4d29ad5c67.pdf.

32 Tulus Tu'u, Etika Dan Pendidikan Seksual (Bandung: Kalam Hidup, 1998), 9-11. 
terhadap seks, karena hal tersebut sudah melekat dalam diri manusia. Kesalahan yang sering terjadi adalah seringkali salah memaknai maksud seks tersebut.

Pandangan Alkitab seks bukanlah sesuatu yang kotor, sebaliknya seks adalah sesuatu yang suci, agung sebagai pemberian dari Allah yang dianugerahkan kepada manusia. ${ }^{33}$ Abineno mengatakan bahwa seks dalam perkawinan itu adalah baik dan indah, menyempurnakan kasih antara laki-laki dan perempuan. ${ }^{34}$ Sebelum kejatuhan manusia dalam dosa Allah menciptakan manusia laki-laki dan perempuan dengan sempurna dalam hal seks. Alkitab memberikan catatan mengenai manusia yang dipersatukan (Kej. 22: 24). Itu artinya pernikahan haruslah antara satu laki-laki dan satu perempuan. ${ }^{35}$

Pada tahun 2011 American Psychiatry Association secara resmi mengadopsi sebuah pedoman baru mengenai homoseksualitas. Beberapa istilah diperkenalkan dan diberi makna yang berbeda antara lain: seks, gender, identitas gender, ekspresi gender, orentasi seksual dan keterbukaan seksual. Terlebih dahulu kita harus mengetahui bahwa ada perbedaan konsep antara gender dan seks. Seks (jenis kelamin) ditentukan secara biologis dan anatomis seseorang atau dengan kata lain seks adalah status biologis seseorang. Indikator yang digunakan adalah bersifat biologis misalnya kromosom, kelenjar reproduksi (sperma untuk laki-laki dan sel telur untuk perempuan), organ reproduksi, intinya seks bersifat biologis. Sedangkan gender merupakan pencirian manusia yang didasarkan pada definisi yang terkait dengan lingkungan sosial, budaya, tempat tinggal, tentunya

33 Christian Bayu Prakoso, Yonatan Alex Arifianto, dan Aji Suseno, "LGBT Dalam Perspektif Alkitab Sebagai Landasan Membentuk Paradigma Etika Kristen Terhadap Pergaulan Orang Percaya," Jurnal Teologi (JUTEOLOG) 1, no. 1 (2020): 1, https://doi.org/10.52489/juteolog.v1i1.8.

34 J.L. Abineno, Buku Katekisasi Sidi Nikah Peneguhan dan Pemberkatannya (Jakarta: BPK Gunung Mulia, 2010), 60.

35 Anon. N. D., Pengakuan Iman Wesminister (Surabaya: Momentum, 2008), x. 
bukan dikaitkan dengan ciri-ciri biologis dari seseorang. Gender adalah perbedaan perilaku seorang laki-laki dan perempuan yang dikonstruksi secara sosial, yakni perbedaan yang bukan diciptakan oleh Tuhan. Gender merupakan sikap, perasaan, perilaku yang diasosiasikan oleh sebuah budaya. Perilaku yang diharapakan sesuai dengan kultural (tempat dimana seseorang itu tinggal) ini disebut dengan gender normative. Sedangkan yang tidak sesuai disebut dengan gender nonkonformitas. ${ }^{36}$ Gender dihubungkan dengan konsep kultural tentang maskulinitas dan femininitas. Untuk membedakan antara seks dan gender banyak orang yang menggunakan istilah "nature" (alamiah/biologis) dan untuk seks dan "nurture" (didikan/asuhan).

James Lola mengatakan LGBT merupakan tindakan perusakan dan perlawanan terhadap wujud gambar rupa Allah dan bahkan lebih daripada itu LGBT merupakan perlawanan dan pemberontakan terhadap Allah yang telah berfirman agar manusia melahirkan keturunan, beranak cucu di muka bumi ini. Hal ini jelas tidak mungkin diwujudkan oleh pelaku LGBT itu sebabnya prilaku demikian tidak dapat dibenarkan karena bertentangan dengan Firman Tuhan. ${ }^{37}$ Kesamaan hakikat sebagai manusia tidak meniadakan perbedaan antara laki-laki dan perempuan. Keduanya sama-sama disebut sebagai "manusia" dan "gambar Allah" (Kej. 1: 26, 27) keduanya diberikan tugas yang sama. Walaupaun demikian perbedaan tidaklah dapat dihindarkan. Hawa diciptakan untuk Adam bukan sebaliknya. Allah tidak hanya menciptakan manusia dengan perbedaan jenis kelamin, namun adanya perbedaan dalam berelasi. Dalam istilah modern Allah

36 Sjanette Eveline, "Transgender dalam Perspektif Teologis Alkitabiah," KALUTEROS: Jurnal Teologi dan Pendidikan Kristen 1, no. 1 (2019): 54, https://doi.org/10.1234/kaluteros.v1i1.6.

37 James Lola, "Teologi Pernikahan Kristen Sebagai Kritik Etis Teologis Terhadap LGBT," KAMASEAN: Jurnal Teologi Kristen 1, no. 2 (2020): 105, https://doi.org/10.34307/kamasean.v1i2.35. 
tidak hanya menentukan seks manusia namun juga menentukan ekspresi gender seturut dengan seks. Adam adalah kepala bukan hawa. Sesudah kejatuhan pun relasi sosial itu tidak berubah, Adam yang diminta pertanggung jawaban oleh Allah (Kej. 3: 9-12). Dari sini dapat dilihat bahwa ketidakselarasan antara seks dan ekspresi gender yang dilakukan oleh kaum LGBT bertabrakan dengan maksud Allah. Perbedaan seksual dimaksudkan sebagai petunjuk bagi perbedaan ekspresi gender.

\section{Hakikat Pernikahan}

Pada penciptaan manusia pertama Adam dan Hawa diciptakan dalam natur yang berbeda, Adam sebagai laki-laki dan Hawa sebagai perempun. Dua natur tersebut tidak kurang ataupun lebih. Dan jelas tujuan penciptaan tersebut adalah untuk menggenapkan rencana Allah yakni beranak cucu, bertambah banyak di muka bumi dan mengusahakan tanah yang diberikan. Untuk mewujudkan hal ini seorang laki-laki dan perempuan disatukan dalam satu ikatan pernikahan sehingga menjadi satu daging. Melihat awal mula penciptaan dan rencana Allah disinilah terlihat jelas bahwa Allah tidak memberi ruang bagi perempuan yang mau hidup dengan sesama jenis atau bagi laki-laki dengan sesama jenisnya. Dan rancangan Allah yang ilahi untuk keintiman seksual bukanlah sembarangan kombinasi. Seorang laki-laki menjadi satu daging dengan seorang perempuan. Manusia adalah mahkluk ciptaan Allah yang tertinggi dan termulia dari segala ciptaan, oleh karena itu manusia tidak berhak merubah kodrat yang sudah diciptakan Allah.

Disepanjang sejarah tidak ada Kitab Suci yang menempatkan kehormatan manusia lebih tepat, lebih tinggi dan lebih sempurna dari apa yang Tuhan telah nyatakan dalam Alkitab. Tidak ada satupun pendiri agama yang mengerti 
kedalaman hakikat dan makna penciptaan manusia sebagai "peta dan teladan Allah". ${ }^{38}$ Demikian apabila ingin memahami karya Allah, maka tidak ada siapapun yang sah menjawab keculi Allah itu sendiri. David dalam bukunya mengatakan ada tiga alasan yang membenarkan jika berpandangan bahwa kejadian 1-2 menegakkan rancangan Allah dalam pernikahan laki-laki dan perempuan. Pertama, perempuan diciptakan sebagai pelengkap yang dirancang secara ilahi bagi laki-laki. Perempuan seperti laki-laki karena diambil dari lakilaki, tetapi sekaligus berbeda dari laki-laki. Kedua, sifat dari persatuan satu daging menegaskan dua orang dengan dua jenis kelamin yang berbeda. Ketiga, hanya dua orang dari jenis kelamin berbeda yang bisa memenuhi tujuan prokreasi dari pernikahan. ${ }^{39}$ Seks adalah karunia luar biasa dan anugerah dari Allah. ${ }^{40}$ Adam tidak meminta pasangan hidup, namun Allah yang melihat, menilai mempertimbangkan dan memberikan pasangan hidup (Kej. 2: 18-25). Adam berperan sebagai penerima, bahkan kemampuan Adam dan Hawa untuk berhubungan seks dan berkembang biak adalah berkat Allah. Jadi sejak awal pernikahan yang dirancang Allah adalah heteroseksual dan monogamis (bdk 1Tim. 4: 4).

\section{Pengaruh Sosiologis Komunitas LGBT}

Sebagai mahkluk sosial yang tidak bisa hidup sendiri maka pada dasarnya manusia berelasi dengan sesamanya. Banyak kebutuhan dalam diri manusia yang seharusnya terpenuhi dengan seimbang. Seorang ahli berpedapat bahwa perilaku LGBT dipengaruhi oleh pola asuh yang salah dari keluarga, hal ini dikemukakan

38 Tong, Rahasia Kemenangan Cinta Dan Seks Menuju Pernikahan, 7.

39 Deyong, Apa Yang Sebenarnya Alkitab Ajarakan Mengenai Homoseksualitas?, 21-24.

40 Stan dan Brena Jones, Bagaima Dan Kapan Memberi Tahu Anak Anda Mengenai Seks? (Surabaya: Momentum, 2012), 1. 
oleh Broumrind yang dikutip oleh Yuniarti bahwa pola asuh orangtua dapat dilihat dari cara orangtua mengontrol anak, memberi hukuman, tidak memberikan hadiah, selalu memerintah anak, serta cara orangtua memberi nasihat. ${ }^{41}$ Pola asuh demikian akan membentuk pribadi dan mental anak saat bertumbuh mencari kenyamanan kepada seseorang yang bisa memperlakukan dengan baik. Seperti yang dikemukakan oleh Bakhoh keluarga seharusnya menjadi lingkunagan untuk mengajar anak-anak tentang hakikat manusia yang bersifat suci dan menunjukan bagaimana anak diperlakukan dalam kasih, dalam kesetiaan dan dalam kesabaran. ${ }^{42}$ Selanjutnya Christopher dan Ferry berpendapat bahwa pola asuh yang salah dari orangtua adalah tidak adanya pendidikan seksual kepada anak mengenai identitas seksual anak sejak kecil. ${ }^{43}$ Disinilah peran keluarga dan gereja harus menyatakan dengan jelas pengertian kekristenan mengenai hakikat seksual manusia, mendorong setiap orang agar pada waktunya menikmati keindahan yang benar serta ada kesadaran menentang penyimpangan seksual. ${ }^{44} \mathrm{Hal}$ ini tentu sangat mempengaruhi perkembangan seorang anak agar bertumbuh dan mengerti penerapan kapan dan kepada siapa orientasi seksual diaplikasikan.

Selanjutnya dalam hal berelasi pun akan membawa pengaruh yang buruk bagi seorang anak apabila bergaul dengan atau berada pada lingkungan yang buruk. Apabila pola asuh yang salah sudah membentuk seorang anak dan masuk dalam komunitas LGBT, maka mereka akan menganggap bahwa hal ini (LGBT)

\footnotetext{
${ }^{41}$ Eka Yanuarti, "Pola asuh Islami orang tua dalam mencegah timbulnya perilaku LGBT sejak usia dini," Cendekia: Jurnal Kependidikan Dan Kemasyarakatan 17, no. 1 (2019): 60, https://doi.org/10.21154/cendekia.v17i1.1337.

42 Bakhoh Jatmiko, "Hakekat Seksualitas Manusia: Perspektif Gereja Kristen Nazarene Di Abad 21 Terhadap Praktek LGBT," Sanctum Domine: Jurnal Teologi 4, no. 1 (2016): 29, https://doi.org/10.46495/sdjt.v4i1.15.

43 Christopher Alexander dan Ferry Simanjuntak, "Pandangan Etika Kristen Terhadap Identitas Homoseksual," Diegesis: Jurnal Teologi 6, no. 1 (2021): 75, https://doi.org/10.46933/DGS.vol6i170-88.

44 Yudhy Sanjaya, "Peranan Orangtua Dalam Mengantisipasi Perilaku Lgbt Di Kalangan Remaja Kristen di Kota Batam," Real Didache 4, no. 1 (2020): 4.
} 
bukanlah peyimpangan yang dilakukan oleh kehendak diri sendiri namun karena sudah merupakan faktor alamiah. Ralph mengemukakan tiga Faktor lingkungan yang mempengaruhi perkembangan seorang anak. ${ }^{45}$ Pertama, secara biologis, emosional, dalam lingkungan keluarga dan masyarakat cukup kuat memberikan pengaruh berkaitan dengan perubahan prilaku dalam pertumbuhan anak. Kedua, hubungan anak dengan orangtua juga mempengaruhi perasaan homoseksual, misalnya saja memperlakukan anak laki-laki seperti perempuan atau sebaliknya. Ketiga, pengalaman masa kecil yang disebabkan oleh pelecehan seksual atau diskrimanasi yang dilakukan dengan sengaja. Alasan secara medis kelompok LGBT memposisikan diri sebagai bagian dari sejak lahir, dan menuntut orang supaya menerima keberadaan karena terlahir LGBT. Sedangkan mereka yang ditolak merasakan diskrimasi dan merasa diperlakukan tidak adil. Melihat hal ini keluarga perlu berperan aktif menyadarkan dan memperhatikan perilaku anak. Keluarga perlu menerima dengan menggunakan pendekatan pribadi. Sedangkan gereja perlu melaksanakan pola pendampingan. Etika sosial dalam bermasyarakat, harus diajarkan sehingga mendukung keluarga dan gereja dalam menolong kelompok LGBT.

\section{KESIMPULAN}

Secara teologis Alkitab mengajarkan bahwa kerusakan natur manusia akibat dosa bersifat komprehensif. Setiap elemen dalam diri manusia telah tercemar oleh dosa, tidak terkecuali dengan tubuh manusia. Jika sakit penyakit kita alami akibat dari dosa secara jasmani maka tidak sulit menerima bahwa

45 Ralph H Gundlach, "Childhood parental relationships and the establishment of gender roles of homosexuals.," Journal of consulting and clinical psychology 33, no. 2 (1969): 136, https://psycnet.apa.org/doi/10.1037/h0027187. 
semua elemen tubuh dalam manusia telah tercemar oleh dosa. Keberadaan kaum LGBT menimbulkan masalah sosial yang mempengaruhi pola perilaku yang normal dalam identitas sebagai manusia yang diciptakan utuh oleh Tuhan, jika menerima LGBT sebagai sebuah hal yang alamiah maka hal ini bertentangan dengan dasar etika Kristen yaitu kebenaran Alkitab. Secara sosiologis kaum LGBT memberikan banyak pengaruh buruk, namun jika terus menyalahkan maka kehilangan kesempatan untuk menolong kaum LGBT. Etika Kristen memandang hal ini sebagai tantangan bagi gereja serta panggilan untuk melayani kaum LGBT bukan sebaliknya menyetujui perilaku mereka. Kita perlu menyadari bahwa kaum LGBT adalah manusia yang diciptakan Allah, maka perlu dilakukan diskusi dalam suasana yang penuh dengan persahabatan, keterbukaan dan kasih. Hal yang lain yang tidak boleh dilupakan adalah tidak semua manusia mendukung pola hidup homoseksualitas, namun dalam perspektif Alkitabiah sebagai dasar etika Kristen, manusia yang menyetujui tanpa menjadi LGBT sama-sama bersalah dihadapan Tuhan. Kaum LGBT perlu diberi kesempatan untuk membaca Alkitab bagi dirinya sendiri dan tidak membiarkan mendengarkan suara teriakan orang yang menyalahkannya. LGBT bukanlah dosa yang paling menjijikkan dan sama dengan pelaku dosa yang biasa (kikir, pemabuk, pemfitnah, pencuri, penyesat, dan lain sebagainya). Pelaku dosa yang "keliatan biasa" tidak lebih baik dari kaum LGBT, sama-sama pendosa. Gereja agar menaruh kasih bersama dan melayani kaum LGBT, karena itu gereja menawarkan tiga hal terhadap kaum LBGT yaitu mengasihi mereka secara pribadi, melakukan pembimbingan agar bertumbuh dalam iman kepada Kristus dan berusaha melakukan tindakan pencegahan. 


\section{DAFTAR PUSTAKA}

Abineno, J.L. Buku Katekisasi Sidi Nikah Peneguhan dan Pemberkatannya. Jakarta: BPK Gunung Mulia, 2010.

Alexander, Christopher, dan Ferry Simanjuntak. "Pandangan Etika Kristen Terhadap Identitas Homoseksual." Diegesis: Jurnal Teologi 6, no. 1 (2021): 70-88. https://doi.org/10.46933/DGS.vol6i170-88.

Borong, Robert S. Etika Seksual Kontemporer, 2006.

Chandra, Xaverius. Etika Sosial (Surabaya: Juli 2016), 4-5. Surabaya: Fakultas Filsafat Widya Mandala, 2016. http://repository.wima.ac.id/id/eprint/14407/7/BAHAN\%20AJARETIKA\%20SOSIAL.pdf.

Cole, Sherwood O. "The Biological Basis of Homosexuality: A Christian Assessment." Journal of Psychology and Theology 23, no. 2 (Juni 1995): 89-100. https://doi.org/10.1177/009164719502300202.

Coles, Gregory. Gay Selibat Kristen. Jawa Timur: Perkantas, 2019.

Consiglio, William. Tidak Lagi Homo. (Bandung, Anggota IKAPI, 1998), 21. Bandung: Kalam Hidup, 1998.

D., Anon. N. Pengakuan Iman Wesminister. Surabaya: Momentum, 2008.

Deyong, Deyong. Apa Yang Sebenarnya Alkitab Ajarakan Mengenai Homoseksualitas? Surabaya: Momentum, 2016.

Ekasari, Silvia. "Potensi Meningkatnya Beban Eonomi Akibat Fenomena Pertumbuhan LGBT di Kota Depok." Jurnal Manajemen Riset Bisnis $\begin{array}{lllll}\text { Indonesia } & 10, & \text { no. } & 6 & \text { (2019): }\end{array}$ https://journal.stiembi.ac.id/index.php/jmrbi/article/view/8/8.

Ermayani, Tri. "LGBT dalam Perspektif Islam." Humanika, Kajian Ilmiah Mata Kuliah Umum 17, no. 2 (2017): 147-68. https://doi.org/10.21831/hum.v17i1.18569.

Eveline, Sjanette. "Transgender dalam Perspektif Teologis Alkitabiah." KALUTEROS: Jurnal Teologi dan Pendidikan Kristen 1, no. 1 (2019): 5461. https://doi.org/10.1234/kaluteros.v1i1.6.

Gunawan, Agung. "Pendampingan Pastoral bagi Kaum Lesbian, Gay, Bisexual dan Transgender." Jurnal Theologi Aletheia 18, no. 1 (2016): 1-13. http://sttaletheia.ac.id/wp-content/uploads/2016/10/PendampinganPastoral-bagi-Kaum-Lesbian-Gay-Bisexual-dan-Transgender.pdf. 
Gundlach, Ralph H. "Childhood parental relationships and the establishment of gender roles of homosexuals." Journal of consulting and clinical psychology 33, no. 2 (1969): $135-53$. https://psycnet.apa.org/doi/10.1037/h0027187.

Handoko, Yakub Tri. Memikirkan Ulang Homoseksualitas. Surabaya: Gratia Fidei, 2016.

Harti, Sri Dwi. "Pentingnya Pelayanan Pastoral Terhadap Korban LGBT." jurnal Luxnos 6, no. 2 (2020): 193-202. https://doi.org/10.47304/jl.v6i2.55.

Hubbard, Thomas K, ed. Homosexuality in Greece and Rome: A Sourcebook of Basic Dokuments. Berkeley: University of California Press, 2003.

Hutabarat, Binsar Antoni. "Evaluasi terhadap Rumusan Pernyataan Pastoral PGI Tentang Lgbt." Societas Dei: Jurnal Agama dan Masyarakat 6, no. 2 (2019): 135-135. https://doi.org/10.33550/sd.v6i2.124.

Jatmiko, Bakhoh. "Hakekat Seksualitas Manusia: Perspektif Gereja Kristen Nazarene Di Abad 21 Terhadap Praktek LGBT." Sanctum Domine: Jurnal Teologi 4, no. 1 (2016): 29-39. https://doi.org/10.46495/sdjt.v4i1.15.

Kinsey, Alfred C, Wardell B Pomeroy, dan Clyde E Martin. "Sexual Behavior In The Human Male." The Journal of Nervous and Mental Disease 109, no. 3 (1949): 283. https://ajph.aphapublications.org/doi/10.2105/AJPH.93.6.894.

Lola, James. "Teologi Pernikahan Kristen Sebagai Kritik Etis Teologis Terhadap LGBT.” KAMASEAN: Jurnal Teologi Kristen 1, no. 2 (2020): 92-106. https://doi.org/10.34307/kamasean.v1i2.35.

Mandimore, Francis M. Natural History of Homosexuality. London: The John Hopkins University Press, 1996.

Miles, Matthew B., A. Michael Huberman, dan Johnny Saldana. Qualitative Data Analysis: A Method Sourbook. Canada: Sage Publication, 2019.

N, N. Tindakan LGBT. Diwawancara oleh Ekker Saogo. Telephone, 2021.

Prakoso, Christian Bayu, Yonatan Alex Arifianto, dan Aji Suseno. "LGBT Dalam Perspektif Alkitab Sebagai Landasan Membentuk Paradigma Etika Kristen Terhadap Pergaulan Orang Percaya." Jurnal Teologi (JUTEOLOG) 1, no. 1 (2020): 1-16. https://doi.org/10.52489/juteolog.v1i1.8.

Saleh, Gunawan, dan Muhammad Arif. "Fenomenologi Sosial Lgbt Dalam Paradigma Agama." Jurnal Riset Komunikasi 1, no. 1 (28 Februari 2018): 88-98. https://doi.org/10.24329/jurkom.v1i1.16.

Sanjaya, Yudhy. "Peranan Orangtua Dalam Mengantisipasi Perilaku Lgbt Di Kalangan Remaja Kristen di Kota Batam.” Real Didache 4, no. 1 (2020): 4. 
Santoso, Meilanny Budiarti. "LGBT dalam Perspektif Hak Asasi Manusia." Share: Social Work Journal 6, no. 2 (2016): 154-272. https://doi.org/10.24198/share.v6i2.13206.

Setiawan, Wawan, dan Yudhitiya Dyah Sukmadewi. "Peran Pancasila Pada Era Globalisasi' Kajian Terhadap Pancasila Dan Fenomena Lgbt (Lesbian, Gay, Bisexual, Transgender) Di Indonesia." Jurnal Dinamika Sosial $\begin{array}{lllll}\text { Budaya } & 19, & \text { no. } & 1 & \text { (2017): }\end{array}$ http://dx.doi.org/10.26623/jdsb.v19i1.691.

Sipayung, Tumini, dan Roma Sihombing. "Pandangan Teologis Terhadap Penyakit Menular Covid-19 Sebagai Problema Global." Lembaga Penelitian dan Pengabdian Masyarakat Politeknik Unggul 7, no. 2 (2020): 325-36. http://politeknikunggul-lppm.ac.id/file/datajurnal/6db19eb3ca9ad55b16d9ae4d29ad5c67.pdf.

Stan, dan Brena Jones. Bagaima Dan Kapan Memberi Tahu Anak Anda Mengenai Seks? Surabaya: Momentum, 2012.

Stewart, Chuck. Homosexuality and Law: A Dictionary. Santa Barbara: Oxford University Press, 2001.

Sutjipto, Subeno. Indahnya Pernikah Kristen. Surabaya: Momentum, 2010.

Tong, Stephen. Rahasia Kemenangan Cinta Dan Seks Menuju Pernikahan. Surabaya: Momentum, 2012.

Tu’u, Tulus. Etika Dan Pendidikan Seksual. Bandung: Kalam Hidup, 1998.

Wedanthi, P, dan IGA Fridari. "Dinamika Kesetiaan Pada Kaum Gay." Jurnal Psikologi Udayana 1, no. 2 (2014): 363-71. https://doi.org/10.24843/JPU.2014.v01.i02.p15.

Wibowo, Ari. "Tinjauan Teoritis Terhadap Wacana Kriminalisasi Lgbt." Jurnal Cakrawala Hukum 11, no. 1 (2017): 96-108. https://ejournal.up45.ac.id/index.php/cakrawalahukum/article/view/191/176.

Yanuarti, Eka. "Pola asuh Islami orang tua dalam mencegah timbulnya perilaku LGBT sejak usia dini." Cendekia: Jurnal Kependidikan Dan Kemasyarakatan 17, no. 1 (2019): 57-80. https://doi.org/10.21154/cendekia.v17i1.1337.

Yulian, Eko. "Text Mining dengan K-Means Clustering pada Tema LGBT dalam Arsip Tweet Masyarakat Kota Bandung." Jurnal Matematika "MANTIK", 4, no. 1 (11 Mei 2018): https://doi.org/10.15642/mantik.2018.4.1.53-58. 